\title{
miR-30a-5p induces the adipogenic differentiation of bone marrow mesenchymal stem cells by targeting FAM13A/Wnt/ק-catenin signaling in aplastic anemia
}

\author{
ENBO WANG $^{1 *}$, YUNYAN ZHANG $^{2 *}$, RONGMEI DING $^{2}$, XIAOHUA WANG ${ }^{1}$, \\ SHUMIN ZHANG ${ }^{1}$ and XINGHUA $\mathrm{LI}^{1}$ \\ Departments of ${ }^{1}$ Blood Transfusion and ${ }^{2}$ Laboratory Medicine, The First People's Hospital of \\ Lianyungang, Lianyungang, Jiangsu 222061, P.R. China
}

Received April 12, 2021; Accepted September 21, 2021

DOI: $10.3892 / \mathrm{mmr} .2021 .12543$

\begin{abstract}
Aplastic anemia (AA) is a bone marrow failure syndrome with high morbidity and mortality. Bone marrow (BM)-mesenchymal stem cells (MSCs) are the main components of the BM microenvironment, and dysregulation of BM-MSC adipogenic differentiation is a pathologic hallmark of AA. MicroRNAs (miRNAs/miRs) are crucial regulators of multiple pathological processes such as AA. However, the role of miR-30a-5p in the modulation of BM-MSC adipogenic differentiation in AA remains unclear. The present study aimed to explore the effect of miR-30a-5p on AA BM-MSC adipogenic differentiation and the underlying mechanism. The levels of miR-30a-5p expression and family with sequence similarity 13, member A (FAM13A) mRNA expression in BM-MSCs were quantified using reverse transcription-quantitative (RT-q) PCR. The mRNA expression levels of adipogenesis-associated factors [fatty acid-binding protein 4 (FABP4), lipoprotein lipase (LPL), perilipin-1 (PLIN1), peroxisome proliferator-activated receptor $\gamma(\mathrm{PPAR} \gamma)$ and CCAAT/enhancer binding protein $\alpha(\mathrm{C} / \mathrm{EBP} \alpha)$ were analyzed using RT-qPCR. Lipid droplet accumulation was evaluated using Oil Red $\mathrm{O}$ staining in BM-MSCs. The interaction between miR-30a-5p and the FAM13A 3'-untranslated region was identified by TargetScan, and a dual-luciferase reporter assay was used to confirm the interaction. The expression levels of FAM13A and Wnt/ $\beta$-catenin pathway-related
\end{abstract}

Correspondence to: $\mathrm{Dr}$ Xinghua Li, Department of Blood Transfusion, The First People's Hospital of Lianyungang, 6 Zhenhua East Road, Lianyungang, Jiangsu 222061, P.R. China

E-mail: xinghua47@126.com

${ }^{*}$ Contributed equally

Abbreviations: AA, aplastic anemia; BM, bone marrow; miRNA/miR, microRNA; MSCs, mesenchymal stem cells; FAM13A, family with sequence similarity 13, member A; 3'-UTR, 3'-untranslated region

Key words: AA, BM-MSCs, adipogenic differentiation, miR-30a-5p, FAM13A, Wnt//-catenin signaling proteins were examined via western blotting. The results showed that miR-30a-5p expression levels were significantly elevated in BM-MSCs from patients with AA compared with those in control subjects (iron deficiency anemia). miR-30a-5p expression levels were also significantly increased in adipose-induced BM-MSCs in a time-dependent manner. miR-30a-5p significantly promoted AA BM-MSC adipogenic differentiation, and significantly enhanced the mRNA expression levels of FABP4, LPL, PLIN1, PPAR $\gamma$ and C/EBP $\alpha$ as well as lipid droplet accumulation. miR-30a-5p was also demonstrated to target FAM13A in AA BM-MSCs. FAM13A significantly reduced BM-MSC adipogenic differentiation by activating the Wnt/ $\beta$-catenin signaling pathway. In conclusion, miR-30a-5p was demonstrated to serve a role in AA BM-MSC adipogenic differentiation by targeting the FAM13A/Wnt/ $\beta$-catenin signaling pathway. These findings suggest that miR-30a-5p may be a therapeutic target for AA.

\section{Introduction}

Aplastic anemia (AA) is a bone marrow failure disorder characterized by peripheral blood pancytopenia and bone marrow (BM) aplasia (1). As the disease progresses, the marrow is severely destroyed, exhibiting enhanced hematopoietic stem/progenitor cell apoptosis, decreased capillaries, excessive adipocytes and reduced BM function (2-4). BM-mesenchymal stem cells (MSCs) serve as multipotent cells with the potential to differentiate into several cells, such as osteoblasts and adipocytes, and constitute the principal cellular components of the BM microenvironment (5). BM-MSCs from patients with AA display fundamental deficiencies that lead to susceptibility to progressive BM failure $(6,7)$. Increasing evidence has revealed that osteogenic-adipose balance dysregulation is associated with the pathophysiological processes of AA (8-10). Therefore, understanding the modulation mechanism of AA BM-MSC adipogenic differentiation is of importance. However, to the best of our knowledge, advancements in this field are still limited.

MicroRNAs (miRNAs/miRs) are small non-coding RNAs with a length of 20-25 nucleotides that influence several biological processes (11). miRNAs can control gene expression 
at the post-transcriptional level by pairing with target mRNAs at the 3'-untranslated region (3'-UTR) (12). miRNAs also modulate numerous targets that have essential functions in a broad spectrum of biological processes, including cell proliferation, apoptosis, differentiation, invasion, metastasis and tumorigenesis (13). Previous studies have revealed that miRNAs are involved in the progression of AA $(14,15)$. miR-1, miR-146b-5p and miR-150-5p serve as biomarkers for the diagnosis of AA (16). miR-144-3p represses BM-MSC osteogenic differentiation in patients with AA by suppressing Tet methylcytosine dioxygenase 2 (17). miR-204 controls AA BM-MSC osteogenic and adipogenic differentiation (18). Furthermore, miR-30a-5p is a well-studied miRNA, and has been shown to serve a role in the development of cancer (19-21). A previous study demonstrated that miR-30a-5p promotes adipocyte differentiation and adipogenesis (22). However, the effect of miR-30a-5p on the adipogenic differentiation of AA BM-MSCs remains unclear.

Family with sequence similarity 13, member A (FAM13A) is highly expressed in thyroid, placenta, duodenum and adipose tissue, and serves as a crucial factor in multiple cellular processes, such as cell proliferation, invasion and differentiation (23-25). Two splicing variants of FAM13A have been identified in humans, namely isoform 1 (v1) and isoform 2 (v2) (26). FAM13A v1 includes a Ras homologous GTPase-activating protein (RhoGAP) domain that is essential for the control of cell survival and proliferation, whereas FAM13A v2 does not carry the RhoGAP domain, suggesting a different function in the control of cellular signaling $(27,28)$. It has been reported that miR-328 in exosomes of M2 macrophages stimulates the development of pulmonary fibrosis by FAM13A (29). FAM13A influences the distribution of body fat and the function of adipocytes, and FAM13A depletion promotes adipocyte differentiation (30). However, the role of FAM13A in the adipogenic differentiation of AA BM-MSCs, and the association between FAM13A and miR-30a-5p remains elusive.

It is well recognized that the Wnt/ $\beta$-catenin signaling pathway is a crucial regulator of MSC osteogenesis and adipogenesis (31). miR-210-3p increases adipogenic differentiation by modulating Wnt signaling in estrogen receptor $\alpha$-deficient MSCs (32). Histone demethylase 7A mediates osteogenic and adipogenic differentiation by regulating Wnt signaling (33). Cysteine-rich protein 61 modulates the adipogenic differentiation of MSCs by mediating canonical Wnt signaling and rapamycin complex 1 (34). Furthermore, it has been determined that FAM13A can activate the Wnt/ $\beta$-catenin signaling pathway (35). miR-30a-5p-targeted PR domain zinc finger protein 1 (PRDM1) regulates Wnt/ $\beta$-catenin signaling in a Dickkopf-1 (DKK1)-dependent manner in glioma development (36). However, the association between Wnt/ $\beta$-catenin signaling, FAM13A and miR-30a-5p in the regulation of $\mathrm{BM}-\mathrm{MSC}$ adipogenic differentiation remains unclear.

The present study aimed to explore the role and underlying mechanism of miR-30a-5p in the modulation of AA BM-MSC adipogenic differentiation. The present results revealed a novel function of miR-30a-5p in promoting adipogenic differentiation of AA BM-MSCs by targeting the FAM13A/Wnt/ $\beta$-catenin signaling pathway.

\section{Materials and methods}

AA clinical samples and AA BM-MSC culture. Human clinical samples of BM, including 11 patients with AA ( 7 men and 4 women; age, 22-48 years) and 14 patients with iron deficiency anemia ( 7 men and 7 women; age, 20-42 years), were obtained from The First People's Hospital of Lianyungang (Lianyungang, China) between January and December 2020 (37). There are several ethical concerns with BM aspiration from healthy donors for MSCs isolation and expansion. Thus, the patients with iron deficiency anemia served as control subjects. All patients provided informed consent for the use of these samples in the present study. The present study conformed to the experimental guidelines of the World Medical Association, and was approved by the Ethics Committee of The First People's Hospital of Lianyungang (approval no. LYGDYYY-2020-017). BM-MSCs were obtained from the BM of patients with AA and control subjects as previously described $(38,39)$. Briefly, BM samples were mixed with DMEM (MilliporeSigma) supplemented with $10 \%$ fetal bovine serum (FBS; MilliporeSigma) at $20^{\circ} \mathrm{C}$ for $30 \mathrm{~min}$. Following centrifugation at $110 \mathrm{x}$ g at $20^{\circ} \mathrm{C}$ for $5 \mathrm{~min}$, the cells were resuspended and maintained in DMEM supplemented with $10 \% \mathrm{FBS}, 0.1 \mathrm{mg} / \mathrm{ml}$ streptomycin (MilliporeSigma) and $100 \mathrm{U} / \mathrm{ml}$ penicillin (MilliporeSigma) at $37^{\circ} \mathrm{C}$ with $5 \% \mathrm{CO}_{2}$. The medium was refreshed every 2-3 days until the cells reached $80 \%$ confluence. BM-MSCs of passage 3 were used in subsequent experiments.

Cell transfection and treatment. Mimic control, miR-30a-5p mimic, inhibitor control, miR-30a-5p inhibitor, lentiviral plasmids containing short hairpin RNA (shRNA/sh) FAM13A or the corresponding scrambled shRNA [sh negative control (NC)] and the vector overexpressing (OE) the FAM13A coding sequence (OE-FAM13A) or the corresponding NC (OENC) were all synthesized by GenScript. The following sequences were used: mimic control, 5'-UUCUCCGAACGUGUCACG UTT-3'; inhibitor control, 5'-CAGUACUUUUGUGUAGUA CAA-3'; miR-30a-5p mimic, 5'-UGUAAACAUCCUCGACUG GAAG-3'; miR-30a-5p inhibitor, 5'-CUUCCAGUCGAGGAU GUUUACA-3'; shNC, 5'-TGAAGCCCTGTCTCATCTTCA ATAT-3'; shFAM13A, 5'-GGAGAACTCTTAGAAAGAA-3'. In brief, BM-MSCs $\left(2 \times 10^{6}\right.$ cells $\left./ \mathrm{ml}\right)$ were seeded into 6-well plates and maintained in DMEM at $37^{\circ} \mathrm{C}$ for $24 \mathrm{~h}$. Mimic control (50 pmol), miR-30a-5p mimic (50 pmol), inhibitor control (50 pmol), miR-30a-5p inhibitor (50 pmol), shFAM13A (5 $\mathrm{nM}), \operatorname{shNC}(5 \mathrm{nM})$, OENC $(5 \mathrm{nM})$ and OE-FAM13A $(5 \mathrm{nM})$ were transfected into BM-MSCs at $37^{\circ} \mathrm{C}$ for $6 \mathrm{~h}$ using Lipofectamine $^{\circledR} 3000$ (Invitrogen; Thermo Fisher Scientific, Inc.) according to the manufacturer's protocol. Following transfection for $48 \mathrm{~h}$, reverse transcription-quantitative PCR (RT-qPCR) was used to determine the transfection efficiency. The Wnt/ $\beta$-catenin signaling inhibitor, DKK1 $(200 \mathrm{ng} / \mathrm{ml}$; PeproTech, Inc.) was added to the medium at $37^{\circ} \mathrm{C}$ for $24 \mathrm{~h}$ when required (40).

Adipogenic differentiation assays. The induction of adipogenic differentiation was initiated as previously described (41-43). Briefly, BM-MSCs ( $3 \times 10^{5}$ cells) were plated in 6-well plates and cultured in an adipogenic medium comprising DMEM supplemented with $0.5 \mathrm{mM}$ 3-isobutyl-1-methyl-xanthine 
(Sigma-Aldrich;MerckKGaA), $10 \%$ FBS, 100 mg/ml indomethacin (MilliporeSigma), $0.01 \mathrm{mg} / \mathrm{ml}$ insulin (MilliporeSigma) and $1 \mathrm{mM}$ dexamethasone (MilliporeSigma) at $37^{\circ} \mathrm{C}$ for 12 days. Adipogenic differentiation was analyzed via the detection of fatty acid-binding protein 4 (FABP4), lipoprotein lipase (LPL), perilipin-1 (PLIN1), peroxisome proliferator-activated receptor $\gamma(\mathrm{PPAR} \gamma)$ and CCAAT/enhancer binding protein $\alpha$ $(\mathrm{C} / \mathrm{EBP} \alpha)$ mRNA expression levels using RT-qPCR.

The accumulation of lipid droplets was measured using Oil Red O staining. Briefly, BM-MSCs were washed twice with PBS at the end of the adipogenic differentiation. Subsequently, cells were fixed with $4 \%$ paraformaldehyde for $30 \mathrm{~min}$ at room temperature and stained with Oil Red $\mathrm{O}$ staining solution (Beijing Solarbio Science \& Technology Co., Ltd.) for $15 \mathrm{~min}$ at room temperature. Images were captured using a light microscope.

$R T$-qPCR. Total RNA was extracted from BM-MSCs cells using TRIzol ${ }^{\circledR}$ reagent (Invitrogen; Thermo Fisher Scientific, Inc.) according to the manufacturer's protocol. Total RNA was reverse transcribed into cDNA using Maxima First Strand cDNA Synthesis kit (Thermo Fisher Scientific, Inc.) according to the manufacturer's protocol. qPCR was subsequently performed using the SYBR Real-Time PCR I Kit (Takara Bio, Inc.) according to the manufacturer's protocol. The reaction conditions were as follows: Initial denaturation at $95^{\circ} \mathrm{C}$ for $10 \mathrm{~min}$, followed by $35 \mathrm{cycles}$ of $94^{\circ} \mathrm{C}$ for $30 \mathrm{sec}, 60^{\circ} \mathrm{C}$ for $50 \mathrm{sec}$ and $72^{\circ} \mathrm{C}$ for $30 \mathrm{sec}$, and final extension at $72^{\circ} \mathrm{C}$ for $10 \mathrm{~min}$. The primer sequences used were as follows: $\mathrm{miR}-30 \mathrm{a}-5 \mathrm{p}$ forward $(\mathrm{F})$, 5'-ACACTCCAGCTGGGTGTAAACATCCTCGAC-3' and miR-30a-5p reverse (R), 5'-CAGTGCGTGTCGTGGAGT-3'; FAM13A F, 5'-ACCCTGTTTGAAGTAGAGTATACAG-3' and FAM13A R, 5'-AGACCTCTTTTACTATGATAAGCCT-3'; C/EBP $\alpha$ F, 5'-TAGGATAACCTTGTGCCTTGGAAAT-3' and C/EBP $\alpha$ R, 5'-GTCTGCTGTAGCCTCGGGAA-3'; PPAR $\gamma$ F, 5'-GCTGACCAAAGCAAAGGCG-3' and PPAR $\gamma$ R, 5'-GCC CTGAAAGATGCGGATG-3'; LPL F, 5'-TCATTCCCGGAG TAGCAGAGT-3' and LPL R, 5'-GGCCACAAGTTTTGGCAC C-3'; PLIN1 F, 5'-GCGAGGATGGCAGTCAACAAA-3' and PLIN1 R, 5'-GCACGCCCTTCTCATAGGCAT-3'; FABP4 F, 5'-ACTGGGCCAGGAATTTGACG-3' and FABP4 R, 5'-CTC GTGGAAGTGACGCCTT-3'; GAPDH F, 5'-AAGAAGGTG GTGAAGCAGGC-3' and GAPDH R, 5'-TCCACCACCCAG TTGCTGTA-3'; and U6 F, 5'-GCTTCGGCAGCACATATA CTAA-3' and U6 R, 5'-AACGCTTCACGAATTTGCGT-3'. The expression levels were normalized to the internal reference genes for miRNA and mRNA, namely U6 and GAPDH, respectively. The $2^{-\Delta \Delta \mathrm{Cq}}$ method was used to quantify the relative expression levels (44).

Dual-luciferase reporter assay. A dual-luciferase reporter assay was used to determine the relationship between miR-30a-5p and FAM13A. The miR-30a-5p-targeted site in the FAM13A 3'-UTR was identified using TargetScan (http://www.targetscan.org/vert_72/). The pmirGLO vectors carrying the wild-type (WT) 3'-UTR of FAM13A and the FAM13A 3'-UTR with the mutant (MUT) miR-30a-5p-binding site were synthesized by Guangzhou RiboBio Co., Ltd. Briefly, the 293T cells were co-transfected with either miR-30a-5p mimic or mimic control, and vectors containing
FAM13A-WT or FAM13A-MUT fragments at $37^{\circ} \mathrm{C}$ for $6 \mathrm{~h}$ using Lipofectamine ${ }^{\circledR} 3000$. After co-transfection, the cells were maintained at $37^{\circ} \mathrm{C}$ for $48 \mathrm{~h}$. Luciferase activity was detected using Dual-Luciferase Assay Kit System (Promega Corporation) and normalized to Renilla luciferase activity.

Western blotting. Total protein was extracted from BM-MSCs using RIPA buffer (Cell Signaling Technology, Inc.). Nuclear and cytoplastic proteins were extracted using the Nuclear and Cytoplastic Protein Extraction Kit (Abbkine Scientific Co., Ltd.). Protein concentrations were measured using a BCA Protein Quantification Kit (Abbkine Scientific Co. Ltd.). Proteins $(30 \mu \mathrm{g})$ were separated by $12 \%$ SDS-PAGE and subsequently transferred onto polyvinylidene difluoride membranes (MilliporeSigma). Membranes were blocked with 5\% skimmed milk for $1 \mathrm{~h}$ at room temperature and incubated overnight at $4^{\circ} \mathrm{C}$ with primary antibodies against FAM13A $(1: 1,000$, cat. no. 55401-1-AP; Wuhan Sanying Biotechnology), total $\beta$-catenin (1:1,000, cat. no. 37447; Cell Signaling Technology, Inc.), non-phospho (active) $\beta$-catenin (1:1,000, cat. no. 19807; Cell Signaling Technology, Inc.), low density lipoprotein receptor-related protein 6 (LRP6; 1:1,000, cat. no. 3395; Cell Signaling technology, Inc.), disheveled segment polarity protein 3 (DVL3; 1:1,000, cat. no. 3218; Cell Signaling Technology, Inc.), histone H3 (1:1,000, cat. no. 17168-1-AP; Wuhan Sanying Biotechnology) and GAPDH (1:5,000, cat. no. 10494-1-AP; Wuhan Sanying Biotechnology), wherein GAPDH and histone H3 served as loading controls. Following the primary incubation, membranes were washed with $0.1 \%$ TBS-Tween-20 (Sigma-Aldrich; Merck KGaA), and then incubated with the corresponding HRP-conjugated goat anti-rabbit IgG (1:2,000, cat. no. SA00001-2; Wuhan Sanying Biotechnology) and HRP-conjugated goat anti-mouse IgG (1:2,000, cat. no. SA00001-1, Wuhan Sanying Biotechnology) secondary antibodies for $1 \mathrm{~h}$ at room temperature. Protein bands were visualized using an Odyssey CLx Infrared Imaging System (LI-COR Biosciences), and protein expression was semi-quantified using ImageJ software (V1.52; National Institutes of Health).

Statistical analysis. Data are presented as the mean \pm SD, and statistical analysis was conducted using GraphPad Prism 7 (GraphPad Software, Inc.). In total, three independent experimental repeats were performed for all experiments. Unpaired Student's t-tests were performed for statistical comparisons between two groups. One-way analysis of variance followed by Tukey's post hoc test was employed for statistical comparisons between more than two groups. The correlation between miR-30a-5p and FAM13A expression levels in AA was analyzed using Pearson's correlation coefficient analysis. $\mathrm{P}<0.05$ was considered to indicate a statistically significant difference.

\section{Results}

miR-30a-5p is upregulated during the adipogenic differentiation of $A A B M-M S C s$. To assess the potential association of miR-30a-5p with BM-MSC adipose differentiation, the miR-30a-5p expression levels in patients with AA were analyzed. miR-30a-5p expression levels were significantly 
elevated in BM-MSCs from patients with AA $(\mathrm{n}=11)$ compared with those of control subjects with iron deficiency anemia $(\mathrm{n}=14 ; \mathrm{P}<0.01$; Fig. 1A). These results implied a possible association between miR-30a-5p and AA BM-MSC adipose differentiation. Furthermore, miR-30a-5p expression levels in day 4 were higher than day 0 ( $\mathrm{P}<0.01$; Fig. $1 \mathrm{~B})$; miR-30a- $5 \mathrm{p}$ expression levels in day 8 were higher than day $4(\mathrm{P}<0.05$; Fig. 1B); miR-30a-5p expression levels in day 12 were higher than day $8(\mathrm{P}<0.01$; Fig. 1B). These data showed that miR-30a-5p expression levels significantly increased in a time-dependent manner in adipose-induced BM-MSCs. Taken together, these findings indicated that miR-30a-5p may serve as a potential modulator in AA BM-MSCs.

miR-30a-5p contributes to the adipogenic differentiation of $A A B M-M S C s$. To further evaluate the effect of miR-30a-5p on the adipogenic differentiation of AA BM-MSCs, AA BM-MSCs were transfected with mimic control or miR-30a-5p mimic, followed by adipose induction for 12 days. As shown in Fig. 2A, the miR-30a-5p mimic increased miR-30a-5p expression compared with mimic control group $(\mathrm{P}<0.01)$, which validated the transfection was successful. The adipogenesis-associated factors FABP4, LPL, PLIN1, PPAR $\gamma$ and $\mathrm{C} / \mathrm{EBP} \alpha$ are known markers of adipogenic differentiation (31). The mRNA expression levels of these proteins were significantly enhanced by miR-30a-5p mimic transfection in BM-MSCs compared with those in the mimic control group $(\mathrm{P}<0.01$; Fig. 2B). Furthermore, Oil Red O staining demonstrated that the miR-30a-5p mimic markedly increased the accumulation of lipid droplets in BM-MSCs ( $\mathrm{P}<0.01$; Fig. 2C). Together, these findings suggested that miR-30a-5p promoted BM-MSC adipose differentiation.

miR-30a-5p targets FAM13A in AA BM-MSCs. The underlying mechanism of miR-30a-5p-regulated adipogenic differentiation of AA BM-MSCs was further investigated. The miR-30a-5p-targeted site in the FAM13A 3'-UTR was identified using TargetScan (Fig. 3A). miR-30a-5p expression levels were significantly negatively correlated with those of FAM13A in AA BM-MSC samples ( $\mathrm{P}=0.0472$; Fig. 3B). These results indicated a potential interaction between miR-30a-5p and FAM13A in the regulation of AA BM-MSCs. Furthermore, miR-30a-5p mimic inhibited the luciferase activity of FAM13A-WT compared with that of the mimic control, whereas no change in luciferase activity was observed upon transfection with FAM13A-MUT $(\mathrm{P}<0.01$; Fig. 3C). In addition, the FAM13A mRNA and protein expression levels were significantly reduced by miR-30a-5p mimic transfection in BM-MSCs $(\mathrm{P}<0.01$; Fig. 3D and E). These results therefore suggested that miR-30a-5p may target FAM13A in AA BM-MSCs.

FAM13A inhibits the adipose differentiation of AA BM-MSCs. To analyze the association of FAM13A with AA BM-MSC adipose differentiation, the FAM13A expression levels in patients with AA were determined. The results demonstrated that FAM13A mRNA expression levels were significantly reduced in BM-MSCs from patients with AA $(n=11)$ compared with those of control subjects with iron deficiency anemia $(\mathrm{n}=14 ; \mathrm{P}<0.05$; Fig. 4A). This implied an inverse association between FAM13A and AA BM-MSC adipogenic

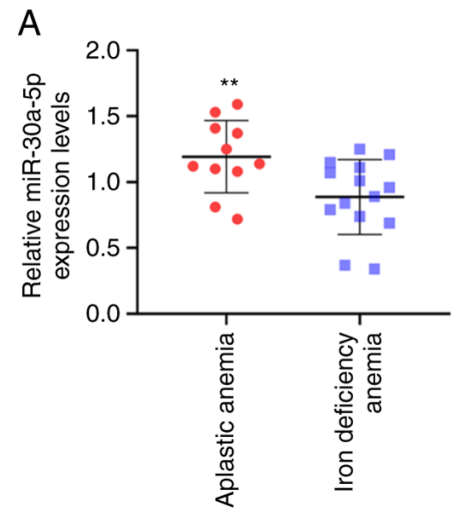

B

Figure 1. miR-30a-5p is upregulated during the adipogenic differentiation of AA BM-MSCs. (A) miR-30a-5p expression levels were quantified using RT-qPCR in BM-MSCs from patients with AA $(n=11)$ and patients with iron deficiency anemia $(n=14)$. (B) miR-30a-5p expression levels were analyzed using RT-qPCR during the adipogenic differentiation of BM-MSCs. Data are presented as the mean $\pm \mathrm{SD}$. ${ }^{* *} \mathrm{P}<0.01$ vs. iron deficiency anemia or day 0 ; ${ }^{\#} \mathrm{P}<0.05$ vs. day 4 ; ${ }^{\& \&} \mathrm{P}<0.01$ vs. day 8 . miR, microRNA; AA, aplastic anemia; BM-MSCs, bone marrow-mesenchymal stem cells; RT-qPCR, reverse transcription-quantitative PCR.

differentiation. AA BM-MSCs were then transfected with lentiviral plasmids carrying shFAM13A or shNC to investigate the function of FAM13A in the adipogenic differentiation of AA BM-MSCs. As shown in Fig. 4B, shFAM13A transfection reduced FAM13A protein expression compared with shNC group $(\mathrm{P}<0.01)$, which verified the transfection was successful. The depletion of FAM13A significantly upregulated the mRNA expression levels of FABP4, LPL, PLIN1, PPAR $\gamma$ and $\mathrm{C} / \mathrm{EBP} \alpha(\mathrm{P}<0.01$; Fig. 4C) compared with those of the shNC group. Furthermore, Oil Red O staining revealed that the accumulation of lipid droplets was markedly enhanced by FAM13A knockdown in BM-MSCs compared with that of the shNC group (Fig. 4D). These results therefore indicated that FAM13A may attenuate AA BM-MSC adipose differentiation.

FAM13A reduces the adipogenic differentiation of BM-MSCs by activating the Wnt/ $\beta$-catenin signaling pathway. The mechanism of FAM13A-mediated AA BM-MSC adipose differentiation was further investigated. It was hypothesized that FAM13A modulated the adipogenic differentiation of AA BM-MSCs via the Wnt/ $\beta$-catenin signaling pathway. FAM13A was overexpressed in AA BM-MSCs. As shown in Fig. 5A, FAM13A protein expression in the OE-FAM13A group was higher than that in the OENC group $(\mathrm{P}<0.01)$, which validated the transfection was successful. The protein expression levels of non-phospho $\beta$-catenin, which is the active state of $\beta$-catenin (45), were significantly enhanced by OE-FAM13A compared with those in the OENC group ( $\mathrm{P}<0.01$; Fig. 5B). However, they were significantly reduced by FAM13A knockdown in AA BM-MSCs compared with those in the shNC group $(\mathrm{P}<0.05)$, while total $\beta$-catenin was unchanged (Fig. 5B). Moreover, FAM13A overexpression significantly promoted the nuclear localization of non-phospho $\beta$-catenin and inhibited the cytoplasmic localization of non-phospho $\beta$-catenin in the cells compared with the findings in the OENC group $(\mathrm{P}<0.01$; GAPDH served as loading controls for the cytoplasmic protein and histone $\mathrm{H} 3$ served as loading controls for the nuclear 
A

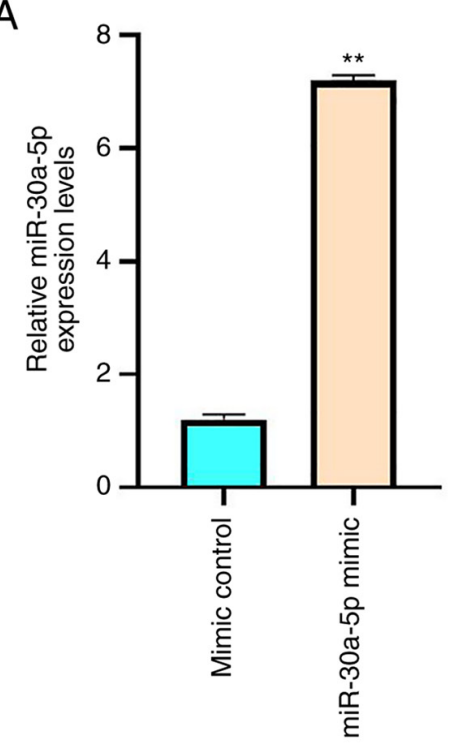

B

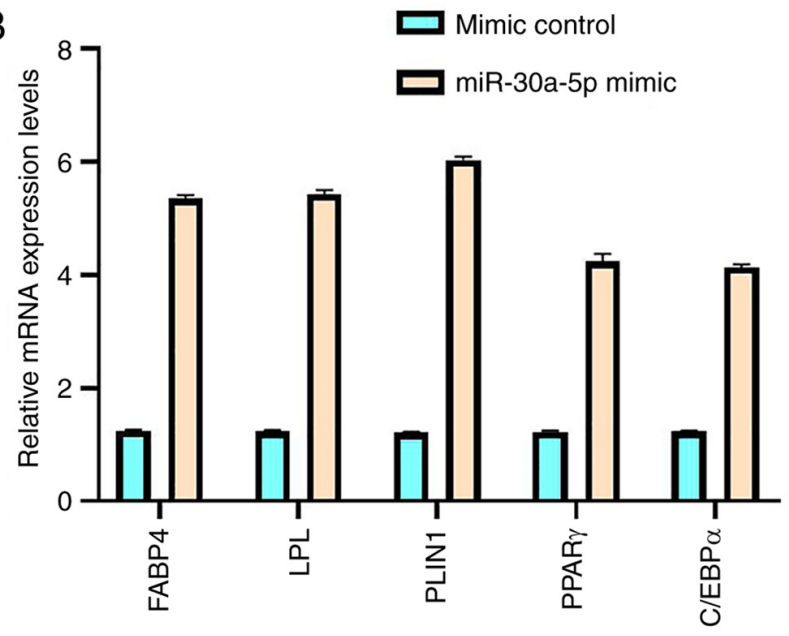

C

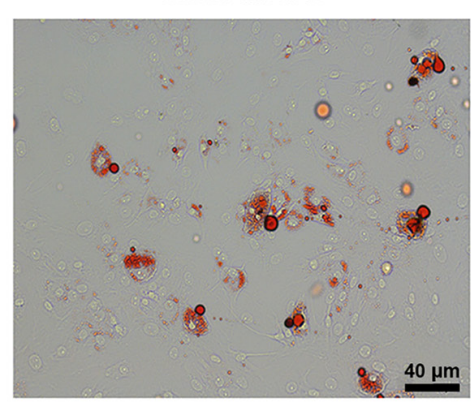

Mimic control

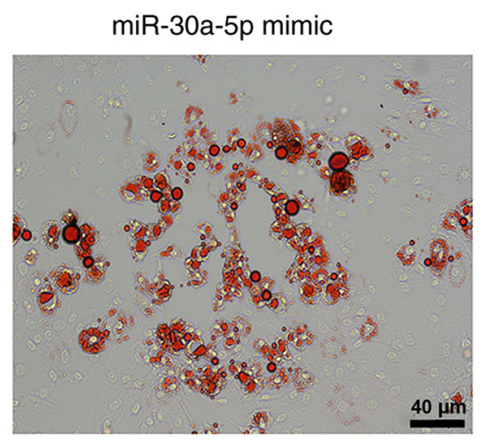

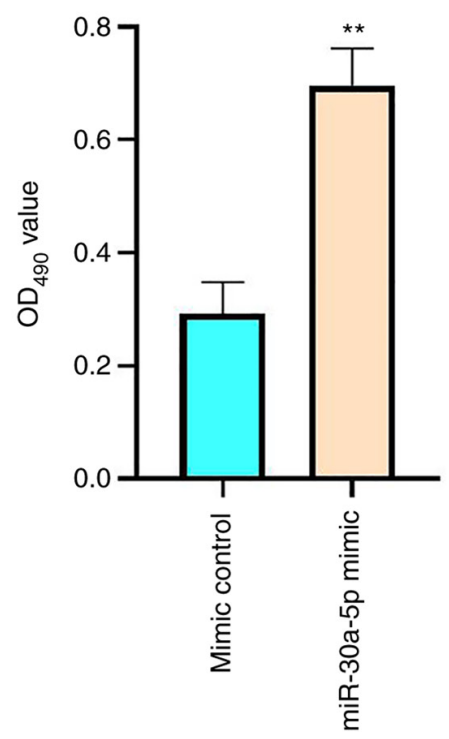

Figure 2. miR-30a-5p contributes to the adipogenic differentiation of AA BM-MSCs. AA BM-MSCs were treated with mimic control or miR-30a-5p mimic. (A) BM-MSC miR-30a-5p expression levels were analyzed using RT-qPCR. (B) BM-MSC FABP4, LPL, PLIN1, PPAR $\gamma$ and C/EBP $\alpha$ mRNA expression levels were analyzed using RT-qPCR. (C) Lipid droplet accumulation was evaluated using Oil Red O staining in BM-MSCs. Data are presented as the mean \pm SD. ${ }^{* *} \mathrm{P}<0.01$ vs. mimic control. miR, microRNA; AA, aplastic anemia; BM-MSCs, bone marrow-mesenchymal stem cells; RT-qPCR, reverse transcription-quantitative PCR; FABP4, fatty acid-binding protein 4; LPL, lipoprotein lipase; PLIN1, perilipin-1; PPAR $\gamma$, peroxisome proliferator-activated receptor $\gamma ; \mathrm{C} / \mathrm{EBP} \alpha, \mathrm{CCAAT} /$ enhancer binding protein $\alpha$.

protein; Fig. 5C). Downstream proteins, including LRP6 and DVL3, were also significantly upregulated by FAM13A overexpression compared with the effects of OENC, and were significantly downregulated by FAM13A knockdown $(\mathrm{P}<0.01$; Fig. 5D). These results indicated that FAM13A activated the Wnt $/ \beta$-catenin signaling pathway in AA BM-MSCs.

DKK1 is an inhibitor of the Wnt/ $\beta$-catenin signaling pathway $(46,47)$. Treatment with DKK1 significantly inhibited the expression of non-phospho $\beta$-catenin enhanced by FAM13A overexpression in AA BM-MSCs compared with OE-FAM13A group $(\mathrm{P}<0.01$; Fig. 5E). Furthermore, Oil Red O staining demonstrated that DKK1 markedly increased the levels of lipid droplets and attenuated FAM13A overexpression-reduced accumulation of lipid droplets in the cells (Fig. 5F). These results therefore suggested that FAM13A reduces the adipose differentiation of BM-MSCs by activating Wnt/ $\beta$-catenin signaling.
miR-30a-5p promotes the adipose differentiation of $A A$ $B M-M S C s$ via FAM13A/Wnt/ $\beta$-catenin signaling. The role of the FAM13A/Wnt/ $\beta$-catenin axis in miR-30a-5p-mediated AA BM-MSC adipose differentiation was determined. For this purpose, BM-MSCs were transfected with miR-30a-5p mimic, OE-FAM13A or miR-30a-5p mimic + OE-FAM13A. 'Control' refers to untreated BM-MSCs. The RT-qPCR results demonstrated that miR-30a-5p mimic significantly reduced FAM13A mRNA expression levels compared with those of the control group, while the FAM13A mRNA expression levels were significantly enhanced by the overexpression of FAM13A in the cells compared with the findings in the miR-30a-5p mimic group ( $\mathrm{P}<0.01$; Fig. 6A). miR-30a-5p mimic also significantly enhanced the mRNA expression levels of FABP4, LPL, PLIN1, PPAR $\gamma$ and $\mathrm{C} / \mathrm{EBP} \alpha$ compared with those of the control $(\mathrm{P}<0.01)$, and the mRNA expression levels of FABP4, LPL, PLIN1, PPAR $\gamma$ and $\mathrm{C} / \mathrm{EBP} \alpha$ were significantly attenuated by 
FAM13A 3'-UTR $5^{\prime}$...UCAUGUCCCCCUUUGUGUUUACU...

miR-30a-5p 3' GAAGGUCAGCUCCUACAAAUGU

FAM13A 3'-UTR MUT $\quad 5^{\prime}$...UCAUGUCCCCCUUUGACAAAUGU... $3^{\prime}$

B

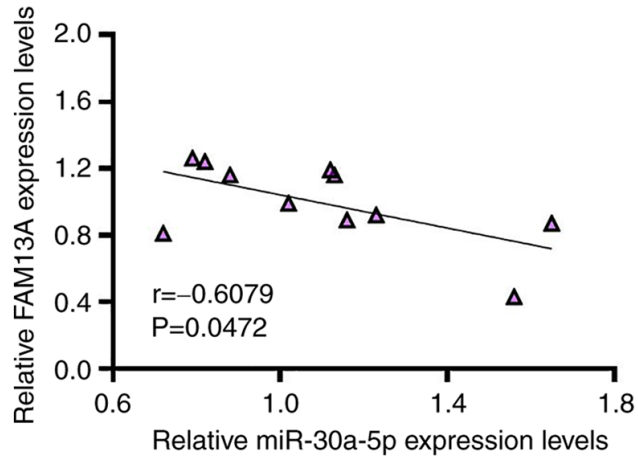

C

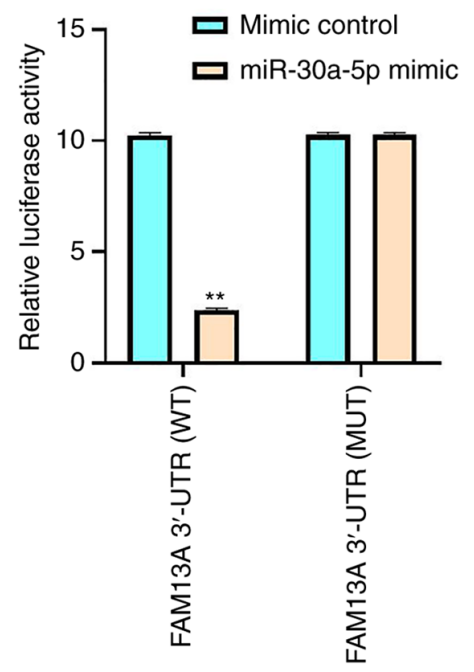

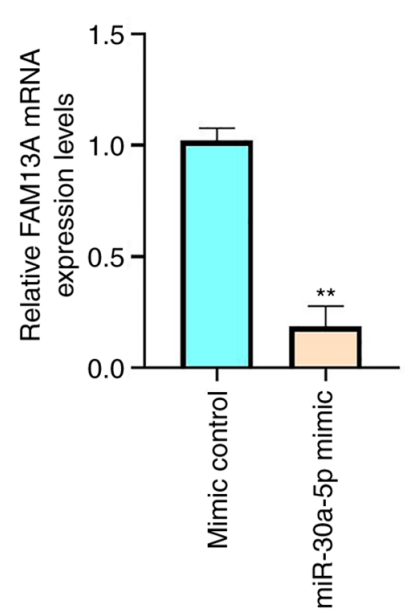

$\mathrm{E}$

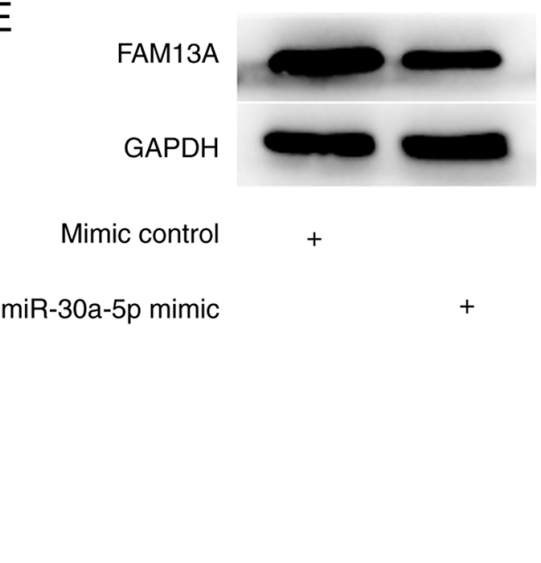



Figure 3. miR-30a-5p targets FAM13A in AA BM-MSCs. (A) The interaction between miR-30a-5p and the FAM13A 3'-UTR was identified by bioinformatic analysis using TargetScan. (B) miR-30a-5p expression was significantly negatively correlated with FAM13A expression in AA BM-MSC samples (n=11). (C) The luciferase activities of FAM13A-WT and FAM13A-MUT were determined using dual-luciferase reporter assays. (D) FAM13A mRNA expression levels were assessed using reverse transcription-quantitative PCR. (E) FAM13A protein expression levels were analyzed via western blotting. Data are presented as the mean $\pm \mathrm{SD} .{ }^{* *} \mathrm{P}<0.01$ vs. mimic control. miR, microRNA; FAM13A, family with sequence similarity 13, member A; AA, aplastic anemia; BM-MSCs, bone marrow-mesenchymal stem cells; UTR, untranslated region; WT, wild-type; MUT, mutant.

FAM13A overexpression in the cells compared with those of the miR-30a-5p mimic group $(\mathrm{P}<0.01$; Fig. $6 \mathrm{~B})$.

Furthermore, the miR-30a-5p mimic markedly increased the accumulation of lipid droplets, and this effect could be blocked by FAM13A overexpression compared with that of the miR-30a-5p mimic group (Fig. 6C). AA BM-MSCs were also transfected with inhibitor control or miR-30a-5p inhibitor. As shown in Fig. 6D, the miR-30a-5p inhibitor reduced miR-30a-5p expression compared with inhibitor control group, which validated the successful transfection $(\mathrm{P}<0.01)$. In addition, miR-30a-5p inhibitor markedly reduced the levels of lipid droplets in AA BM-MSCs, while DKK1 treatment rescued this phenotype (Fig. 6E). Together, these results suggested that $\mathrm{miR}-30 \mathrm{a}-5 \mathrm{p}$ contributes to the adipose differentiation of AA BM-MSCs by regulating the FAM13A/Wnt/ $\beta$-catenin axis.

\section{Discussion}

AA is a severe hypocellularity of the BM characterized by pancytopenia of the peripheral blood (48). MSCs serve as essential precursor cells of the BM microenvironment, and differentiate into numerous types of stromal cells, including osteoclasts, fibroblasts, endothelial cells and adipocytes, thus providing a suitable framework and a complex system of extracellular matrix proteins, adhesion molecules and cytokines (49-51). Fatty BM and aberrant hematopoiesis are the pathological hallmarks of AA, and the mechanisms of AA adipose-osteogenic modulation are complex $(52,53)$. As main members of the family of non-coding RNAs and a important regulators of physiological and pathological processes, miRNAs are involved in the modulation of AA progression. For example, PPAR $\gamma$-regulated miR-199a-5p 
A
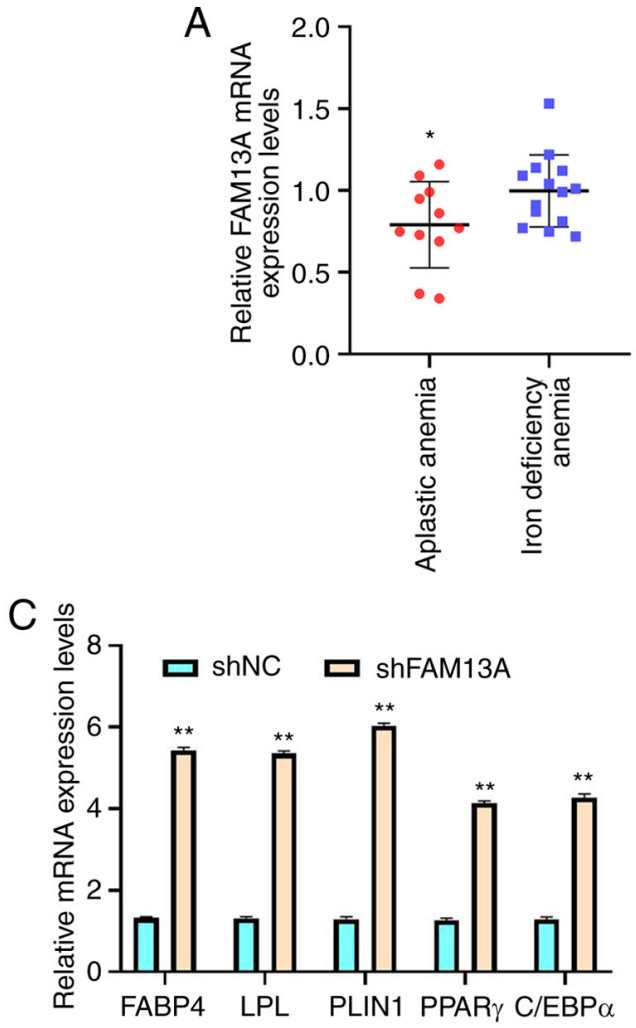

B



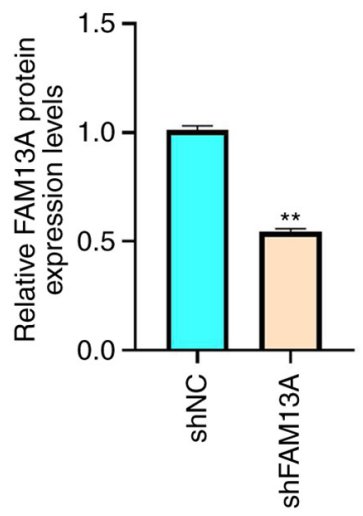

D

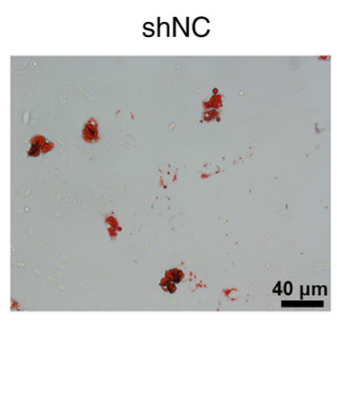

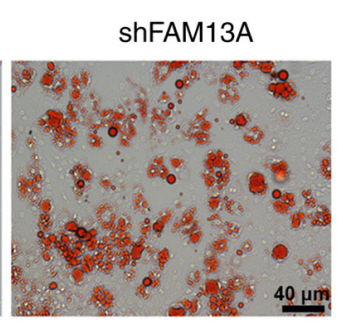

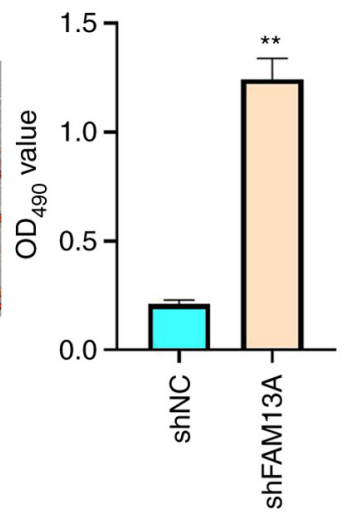

Figure 4. FAM13A inhibits the adipogenic differentiation of AA BM-MSCs. (A) FAM13A mRNA expression levels were analyzed using RT-qPCR in BM-MSCs from patients with AA $(n=11)$ and patients with iron deficiency anemia $(n=14)$. (B-D) BM-MSCs were treated with lentiviral plasmids carrying shFAM13A or shNC. (B) The protein expression levels of FAM13A were examined by western blotting. (C) FABP4, LPL, PLIN1, PPAR $\gamma$ and C/EBP $\alpha$ mRNA expression levels were analyzed using RT-qPCR. (D) Lipid droplet accumulation was evaluated by Oil Red O staining. Data are presented as the mean \pm SD. ${ }^{*} \mathrm{P}<0.05$ vs. iron deficiency anemia; ${ }^{* *} \mathrm{P}<0.01$ vs. shNC. FAM13A, family with sequence similarity 13 , member A; AA, aplastic anemia; BM-MSCs, bone marrow-mesenchymal stem cells; RT-qPCR, reverse transcription-quantitative PCR; sh, short hairpin; NC, negative control; FABP4, fatty acid-binding protein 4; LPL, lipoprotein lipase; PLIN1, perilipin-1; PPAR $\gamma$, peroxisome proliferator-activated receptor $\gamma$; C/EBP $\alpha$, CCAAT/enhancer binding protein $\alpha$.

contributes to the adiposity of BM in AA (38). Maternally expressed 3 regulates the expression of $\mathrm{T}$ cell immunoreceptor with Ig and ITIM domains and the activation of CD4 ${ }^{+}$ T cells by sponging miR-23a (54). miR-126-5p may serve as a diagnostic biomarker for AA (55), while miR-1202 is significantly upregulated in patients with AA, and can potentially target endo- $\alpha-1,2-$ mannosidase and Rap guanine nucleotide exchange factor 5 (15). IL-11 increases the efficacy of hematopoietic stem cell transplant treatment in an AA mouse model by modulating the NF- $\kappa \mathrm{B} / \mathrm{miR}-204 /$ thrombopoietin signaling pathway (56). miR-204 is involved in modulating the adipogenic differentiation of AA MSCs (18). Moreover, it has been reported that miR-30a-5p enhances adipocyte differentiation and adipogenesis (22). The present results demonstrated that miR-30a-5p was significantly elevated in the BM-MSCs of patients with AA and in adipose-induced BM-MSCs. Moreover, overexpression of miR-30a-5p promoted the expression of adipogenesis-associated factors (FABP4, LPL, PLIN1, PPAR $\gamma$ and $\mathrm{C} / \mathrm{EBP} \alpha$ ) and increased the number of lipid droplets in BM-MSCs. These data presented a novel function of miR-30a-5p in the adipogenic differentiation of BM-MSCs, providing valuable evidence for the fundamental role of miRNAs in the progression of AA.
FAM13A, an important factor in the modulation of metabolic homeostasis, modulates insulin sensitivity and maintains metabolism homeostasis in adipocytes $(57,58)$. FAM13A also regulates lipid metabolism and hepatic glucose by suppressing AMP-activated protein kinase activity (59). Obesity-related FAM13A is essential for insulin sensitivity and adipose development (60). FAM13A influences fat administration and adipocyte capacity, while FAM13A knockdown stimulates adipogenic differentiation (30). The present study demonstrated that FAM13A was downregulated in the BM-MSCs of patients with AA, and FAM13A was targeted by miR-30a-5p in AA BM-MSCs. In addition, knockdown of FAM13A promoted the expression of adipogenesis-associated factors (FABP4, LPL, PLIN1, PPAR $\gamma$ and C/EBP $\alpha$ ) and increased the number of lipid droplets in BM-MSCs, and overexpression of FAM13A reversed the promotive effects of miR-30a-5p mimic on the expression of adipogenesis-associated factors and the number of lipid droplets. These data suggested a novel role of FAM13A in the modulation of AA BM-MSCs.

As a fundamental cellular pathway, the role of $\mathrm{Wnt} / \beta$-catenin signaling in adipogenic differentiation has been well characterized (61). It has been previously reported that the activation of Wnt/ $\beta$-catenin signaling inhibits the adipogenic differentiation of AA BM-MSCs (62). Taurine transporters control the 
A
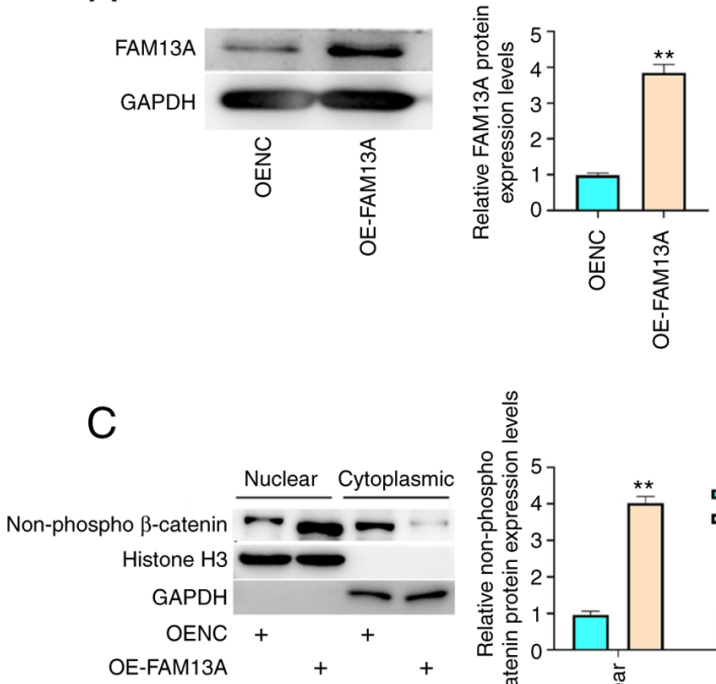

$E$

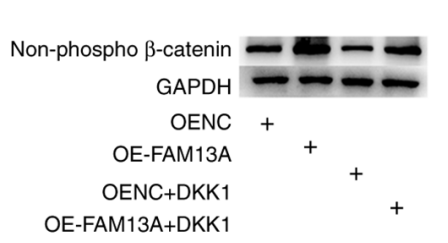

B
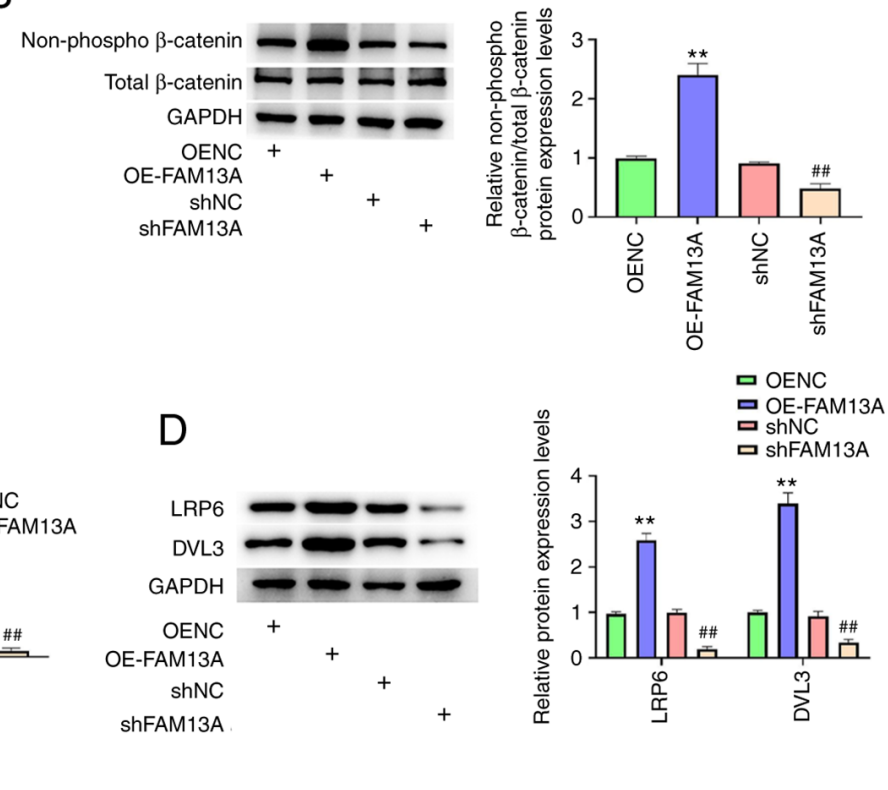

F
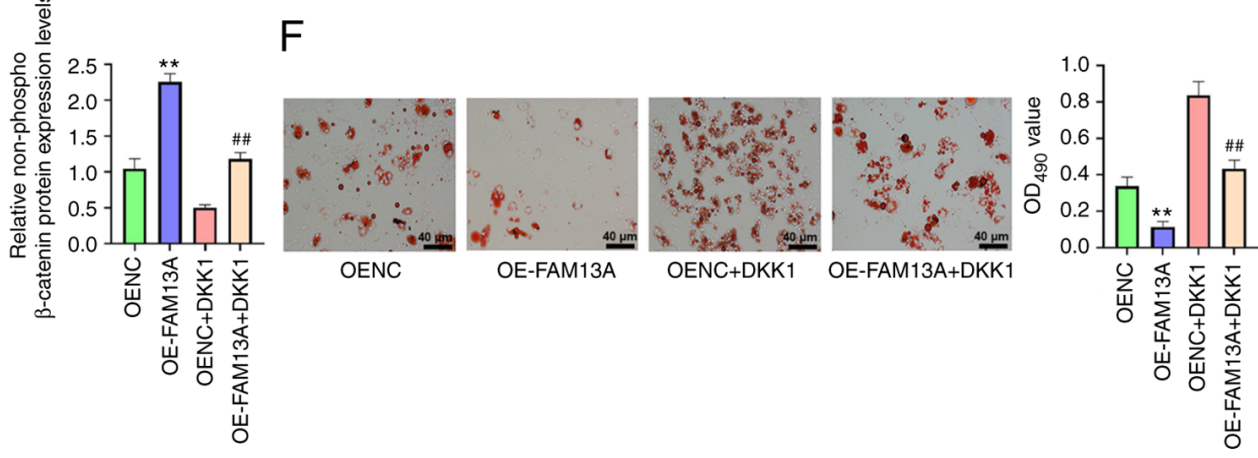

Figure 5. FAM13A reduces the adipogenic differentiation of BM-MSCs by activating the Wnt/ $\beta$-catenin signaling pathway. (A) AA BM-MSCs were transfected with OENC or OE-FAM13A. FAM13A protein expression levels were analyzed via western blotting. (B) Total $\beta$-catenin and non-phospho $\beta$-catenin protein expression levels were analyzed via western blotting. (C) The nuclear and cytoplasmic protein expression levels of non-phospho $\beta$-catenin were analyzed via western blotting. (D) The protein expression levels of LRP6 and DVL3 were analyzed via western blotting analysis. (E and F) AA BM-MSCs were transfected with OENC or OE-FAM13A with or without DKK1 treatment. (E) Non-phospho $\beta$-catenin protein expression levels were determined via western blotting. (F) Lipid droplet accumulation was analyzed by Oil Red O staining. Data are presented as mean $\pm \mathrm{SD}$. ${ }^{* *} \mathrm{P}<0.01 \mathrm{vs}$. OENC; ${ }^{\# \#} \mathrm{P}<0.01 \mathrm{vs}$. shNC or OE-FAM13A. FAM13A, family with sequence similarity 13, member A; AA, aplastic anemia; BM-MSCs, bone marrow-mesenchymal stem cells; sh, short hairpin; LRP6, low density lipoprotein receptor-related protein 6; DVL3, disheveled segment polarity protein 3; OE, overexpression; NC, negative control; DKK1, Dickkopf-related protein 1.

adipogenic differentiation of adipose stem cells by modifying Wnt// -catenin signaling (63). Lysine demethylase 4A modulates osteogenic and adipogenic differentiation via epigenetic modification of Wnt signaling (64). miR-196a represses the adipogenic differentiation of adipose stem cells by controlling Wnt $/ \beta$-catenin signaling (65). Furthermore, polydatin increases MSC osteogenic differentiation by stimulating the bone morphogenetic protein 2-Wnt/ $\beta$-catenin pathway (66). miR-199a-3p controls BM-MSC adipose differentiation by regulating the $\mathrm{Wnt} / \beta$-catenin signaling pathway (67). The present study demonstrated that FAM13A activated the Wnt/ $\beta$-catenin signaling pathway in AA BM-MSCs. Moreover, DKK1 (an inhibitor of the Wnt/ $/$-catenin signaling pathway) reversed the inhibitive role of FAM13A overexpression or miR-30a-5p knockdown on the number of lipid droplets. Taken together, miR-30a-5p contributed to AA BM-MSC adipose differentiation by modulating the FAM $13 \mathrm{~A} / \mathrm{Wnt} / \beta$-catenin signaling pathway. The current findings provided novel evidence that $\mathrm{Wnt} / \beta$-catenin signaling serves an important role in the regulation of adipogenic differentiation in AA BM-MSCs.

However, there were some shortcomings in the present study. Firstly, the size of BM samples was small, and future studies should expand the sample size and include samples of healthy donors. Secondly, the effects of DKK1 alone on BM-MSCs have not been clearly investigated, which therefore warrants intensive study in the future.

In conclusion, miR-30a-5p was upregulated in the BM-MSCs of patients with AA and adipose-induced BM-MSCs. Moreover, miR-30a-5p promoted the adipogenic differentiation of AA BM-MSCs, which may be involved in the FAM13A/Wnt/ $\beta$-catenin signaling. These results provide a theoretical basis for the mechanism by which miR-30a-5p and FAM13A modulate AA BM-MSC adipose differentiation and provide promising therapeutic targets for AA treatment. 

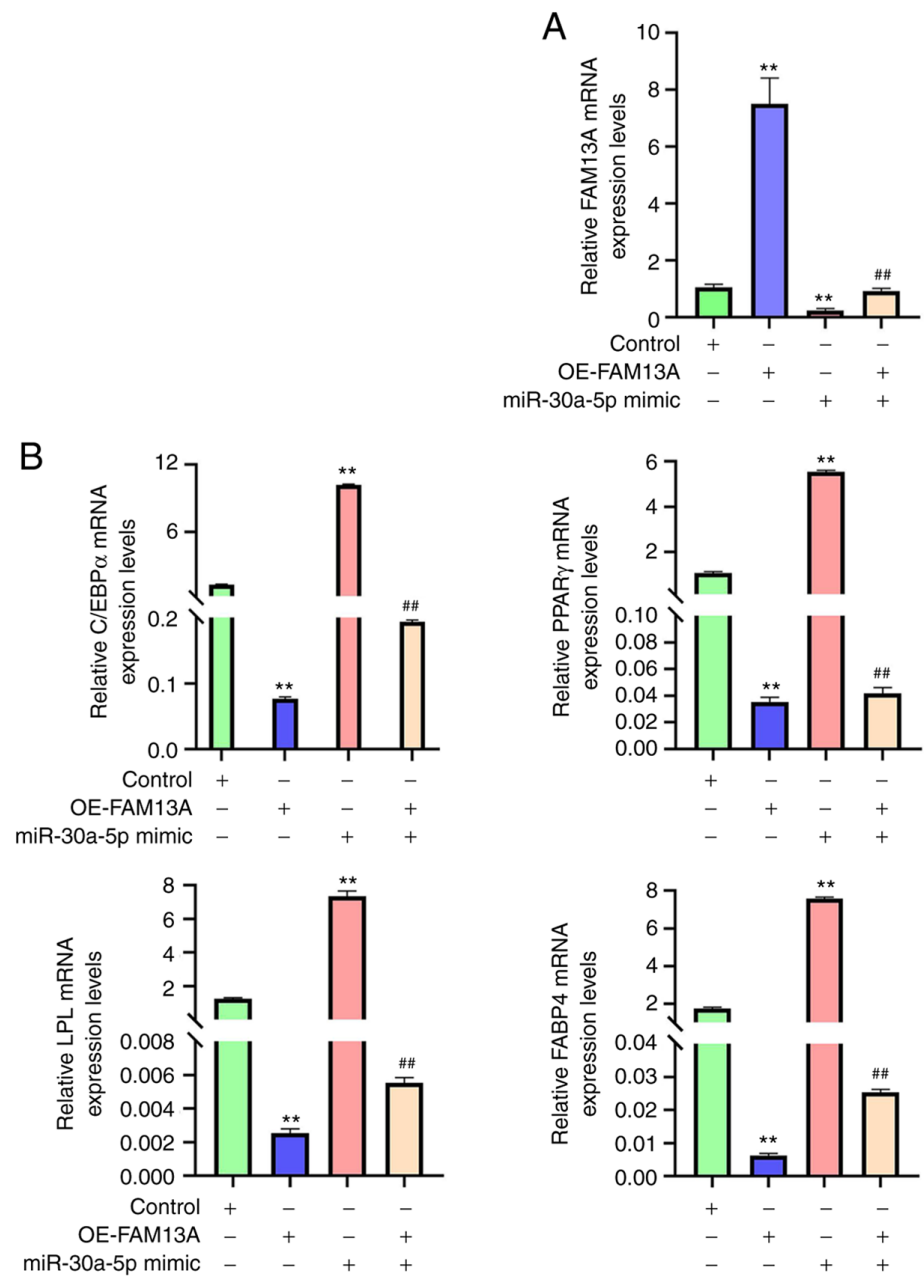

C


$\mathrm{E}$
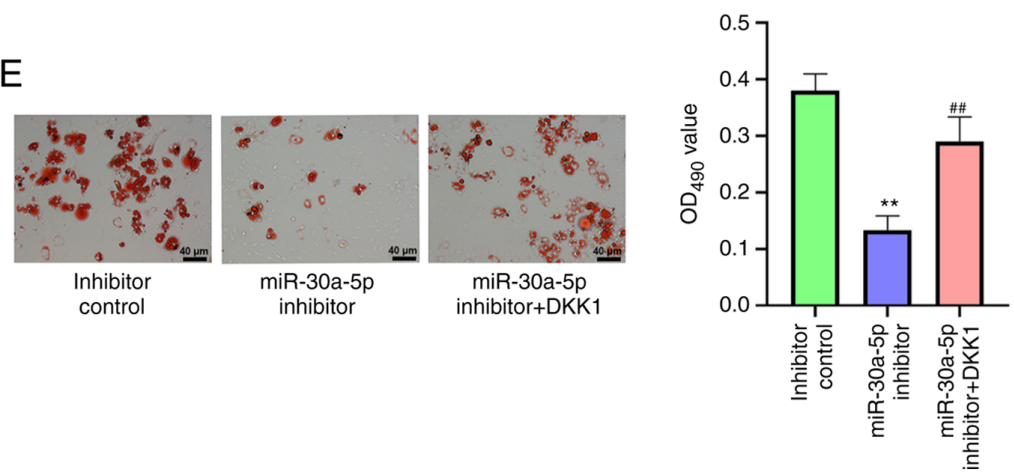

Figure 6. miR-30a-5p promotes the adipogenic differentiation of AA BM-MSCs via the FAM13A/Wnt/ $/$-catenin signaling pathway. (A-C) AA BM-MSCs were treated with OE-FAM13A, miR-30a-5p mimic or miR-30a-5p mimic + OE-FAM13A; in the control group, AA BM-MSCs were not treated. (A) FAM13A mRNA expression levels were analyzed using RT-qPCR. (B) mRNA expression levels of C/EBP $\alpha$, PPAR $\gamma$, PLIN1, LPL and FABP4 were analyzed using RT-qPCR. (C) Lipid droplet accumulation was determined using Oil Red O staining. (D) miR-30a-5p expression levels were analyzed using RT-qPCR in BM-MSCs transfected with control inhibitor or miR-30a-5p inhibitor. (E) Lipid droplet accumulation was determined using Oil Red O staining in AA BM-MSCs treated with inhibitor control, miR-30a-5p inhibitor, or co-treated with miR-30a-5p inhibitor and DKK1. Data are presented as the mean \pm SD. ${ }^{* *} \mathrm{P}<0.01$ vs. control or inhibitor control; ${ }^{\# /} \mathrm{P}<0.01$ vs. miR-30a-5p mimic or miR-30a-5p inhibitor. miR, microRNA; AA, aplastic anemia; BM-MSCs, bone marrow-mesenchymal stem cells; FAM13A, family with sequence similarity 13 , member A; OE, overexpression; RT-qPCR, reverse transcription-quantitative PCR; FABP4, fatty acid-binding protein 4; LPL, lipoprotein lipase; PLIN1, perilipin-1; PPAR $\gamma$, peroxisome proliferator-activated receptor $\gamma$; C/EBP $\alpha$, CCAAT/enhancer binding protein $\alpha$. 


\section{Acknowledgements}

Not applicable.

\section{Funding}

No funding was received.

\section{Availability of data and materials}

The datasets used and/or analyzed during the current study are available from the corresponding author on reasonable request.

\section{Authors' contributions}

EW and XL designed the study; YZ and RD performed the research; XW and SZ analyzed the data; and XL wrote the manuscript. All authors read and approved the final manuscript. YZ and RD confirm the authenticity of all the raw data.

\section{Ethics approval and consent to participate}

The present study was approved by the Ethics Committee of The First People's Hospital of Lianyungang (approval no. LY GDYYY-2020-017). All patients signed the written informed consent form.

\section{Patient consent for publication}

Not applicable.

\section{Competing interests}

The authors declare that they have no competing interests.

\section{References}

1. Bacigalupo A: How I treat acquired aplastic anemia. Blood 129: 1428-1436, 2017.

2. Savage SA, Viard M, O'hUigin C, Zhou W, Yeager M, Li SA, Wang T, Ramsuran V, Vince N, Vogt A, et al: Genome-wide association study identifies HLA-DPB1 as a significant risk factor for severe aplastic anemia. Am J Hum Genet 106: 264-271, 2020

3. Wang L and Liu H: Pathogenesis of aplastic anemia. Hematology 24 : 559-566, 2019.

4. Shallis RM, Ahmad R and Zeidan AM: Aplastic anemia: Etiology, molecular pathogenesis, and emerging concepts. Eur J Haematol 101: 711-720, 2018.

5. Nombela-Arrieta C, Ritz J and Silberstein LE: The elusive nature and function of mesenchymal stem cells. Nat Rev Mol Cell Biol 12: 126-131, 2011.

6. Li J, Lu S, Yang S, Xing W, Feng J, Li W, Zhao Q, Wu H, Ge M, Ma F, et al: Impaired immunomodulatory ability of bone marrow mesenchymal stem cells on CD4(+) T cells in aplastic anemia. Results Immunol 2: 142-147, 2012.

7. Li J, Yang S, Lu S, Zhao H, Feng J, Li W, Ma F, Ren Q, Liu B, Zhang L, et al: Differential gene expression profile associated with the abnormality of bone marrow mesenchymal stem cells in aplastic anemia. PLoS One 7: e47764, 2012.

8. Cheng HC, Liu SW, Li W, Zhao XF, Zhao X, Cheng M, Qiu L and Ma J: Arsenic trioxide regulates adipogenic and osteogenic differentiation in bone marrow MSCs of aplastic anemia patients through BMP4 gene. Acta Biochim Biophys Sin (Shanghai) 47: 673-679, 2015

9. Tripathy NK, Singh SP and Nityanand S: Enhanced adipogenicity of bone marrow mesenchymal stem cells in aplastic anemia. Stem Cells Int 2014: 276862, 2014
10. Deng S, Zeng Y, Wu L, Hu Z, Shen J, Shen Y, Shen Y, Zhou Y, Chen J and Lin S: The regulatory roles of VEGF-Notch signaling pathway on aplastic anemia with kidney deficiency and blood stasis. J Cell Biochem: Sep 19, 2018 (Epub ahead of print).

11. Lu TX and Rothenberg ME: MicroRNA. J Allergy Clin Immunol 141: 1202-1207, 2018

12. Zhou Q, Huang SX, Zhang F, Li SJ, Liu C, Xi YY, Wang L, Wang X, He QQ, Sun CC and Li DJ: MicroRNAs: A novel potential biomarker for diagnosis and therapy in patients with non-small cell lung cancer. Cell Prolif 50: e12394, 2017.

13. Rupaimoole R and Slack FJ: MicroRNA therapeutics: Towards a new era for the management of cancer and other diseases. Nat Rev Drug Discov 16: 203-222, 2017.

14. Wang Y, Niu ZY, Guo YJ, Wang LH, Lin FR and Zhang JY: IL-11 promotes the treatment efficacy of hematopoietic stem cell transplant therapy in aplastic anemia model mice through a NF- $\mathrm{kB} /$ microRNA-204/thrombopoietin regulatory axis. Exp Mol Med 49: e410, 2017.

15. Adhikari S and Mandal P: Integrated analysis of global gene and microRNA expression profiling associated with aplastic anaemia. Life Sci 228: 47-52, 2019.

16. Hosokawa K,KajigayaS,Feng X,DesiertoMJ,FernandezIbanez MD, Rios O, Weinstein B, Scheinberg P, Townsley DM and Young NS: A plasma microRNA signature as a biomarker for acquired aplastic anemia. Haematologica 102: 69-78, 2017.

17. Li N, Liu L, Liu Y, Luo S, Song Y and Fang B: miR-144-3p suppresses osteogenic differentiation of BMSCs from patients with aplastic anemia through repression of TET2. Mol Ther Nucleic Acids 19: 619-626, 2020

18. Zhao J, Wang C, Song Y and Fang B: Arsenic trioxide and microRNA-204 display contrary effects on regulating adipogenic and osteogenic differentiation of mesenchymal stem cells in aplastic anemia. Acta Biochim Biophys Sin (Shanghai) 46: 885-893, 2014

19. Zhu J, Zeng Y, Li W, Qin H, Lei Z, Shen D, Gu D, Huang JA and Liu Z: CD73/NT5E is a target of miR-30a-5p and plays an important role in the pathogenesis of non-small cell lung cancer. Mol Cancer 16: 34, 2017.

20. Li L, Kang L, Zhao W, Feng Y, Liu W, Wang T, Mai H, Huang J, Chen S, Liang Y, et al: miR-30a-5p suppresses breast tumor growth and metastasis through inhibition of LDHA-mediated Warburg effect. Cancer Lett 400: 89-98, 2017.

21. Murinello S, Usui Y, Sakimoto S, Kitano M, Aguilar E, Friedlander HM, Schricker A, Wittgrove C, Wakabayashi Y, Dorrell MI, et al: miR-30a-5p inhibition promotes interaction of Fas+ endothelial cells and FasL+ microglia to decrease pathological neovascularization and promote physiological angiogenesis. Glia 67: 332-344, 2019.

22. Cui S, Soni CB, Xie J, Li Y, Zhu H, Wu F and Zhi X: MiR-30a-5p accelerates adipogenesis by negatively regulating Sirtuin 1 . Int J Clin Exp Pathol 11: 5203-5212, 2018.

23. Corvol H, Hodges CA, Drumm ML and Guillot L: Moving beyond genetics: Is FAM13A a major biological contributor in lung physiology and chronic lung diseases? J Med Genet 51: 646-649, 2014.

24. Liang C, Li A, Raza SHA, Khan R, Wang X, Wang S, Wang G, Zhang Y and Zan L: The Molecular characteristics of the FAM13A gene and the role of transcription factors ACSL1 and ASCL2 in its core promoter region. Genes (Basel) 10: 981, 2019.

25. Lin X, Li Y, Gong L, Yun JH, Xu S, Tesfaigzi Y, Qiao D and Zhou X: Tempo-spatial regulation of the Wnt pathway by FAM13A modulates the stemness of alveolar epithelial progenitors. EBioMedicine 69: 103463, 2021.

26. Eisenhut F, Heim L, Trump S, Mittler S, Sopel N, Andreev K, Ferrazzi F, Ekici AB, Rieker R, Springel R, et al: FAM13A is associated with non-small cell lung cancer (NSCLC) progression and controls tumor cell proliferation and survival. Oncoimmunology 6: e1256526, 2017.

27. Zhang Y, Wang S, Wang C, Xiao J, Zhang S and Zhou H: High expression of FAM13A was associated with increasing the liver cirrhosis risk. Mol Genet Genomic Med 7: e543, 2019.

28. Corvol H, Rousselet N, Thompson KE, Berdah L, Cottin G, Foussigniere T, Longchampt E, Fiette L, Sage E, Prunier C, et al: FAM13A is a modifier gene of cystic fibrosis lung phenotype regulating rhoa activity, actin cytoskeleton dynamics and epithelial-mesenchymal transition. J Cyst Fibros 17: 190-203, 2018.

29. Yao MY, Zhang WH, Ma WT, Liu QH, Xing LH and Zhao GF: microRNA-328 in exosomes derived from M2 macrophages exerts a promotive effect on the progression of pulmonary fibrosis via FAM13A in a rat model. Exp Mol Med 51: 1-16, 2019. 
30. Fathzadeh M, Li J, Rao A, Cook N, Chennamsetty I, Seldin M, Zhou X, Sangwung P, Gloudemans MJ, Keller M, et al: FAM13A affects body fat distribution and adipocyte function. Nat Commun 11: 1465, 2020

31. Park E, Kim J, Yeo S, Kim G, Ko EH, Lee SW, Li WY, Choi CW and Jeong SY: Antiadipogenic effects of loganic Acid in 3T3-L1 preadipocytes and ovariectomized mice. Molecules 23: 1663 2018.

32. Li X, Peng B, Zhu X, Wang P, Sun K, Lei X, He H, Tian Y, Mo S, Zhang R and Yang L: MiR-210-3p inhibits osteogenic differentiation and promotes adipogenic differentiation correlated with Wnt signaling in ER $\alpha$-deficient rBMSCs. J Cell Physiol 234: 23475-23484, 2019.

33. Yang X, Wang G, Wang Y, Zhou J, Yuan H, Li X, Liu Y and Wang B: Histone demethylase KDM7A reciprocally regulates adipogenic and osteogenic differentiation via regulation of $\mathrm{C} / \mathrm{EBP} \alpha$ and canonical Wnt signalling. J Cell Mol Med 23 2149-2162, 2019.

34. Yang Y, Qi Q, Wang Y, Shi Y, Yang W, Cen Y, Zhu E, Li X, Chen D and Wang B: Cysteine-rich protein 61 regulates adipocyte differentiation from mesenchymal stem cells through mammalian target of rapamycin complex 1 and canonical Wnt signaling. FASEB J 32: 3096-3107, 2018.

35. Jin Z, Chung JW, Mei W, Strack S, He C, Lau GW and Yang J: Regulation of nuclear-cytoplasmic shuttling and function of Family with sequence similarity 13, member A (Fam13a), by B56-containing PP2As and Akt. Mol Biol Cell 26: 1160-1173, 2015.

36. Wang X, Wang K, Han L, Zhang A, Shi Z, Zhang K, Zhang H, Yang $\mathrm{S}, \mathrm{Pu} \mathrm{P}$, Shen $\mathrm{C}$, et al: PRDM1 is directly targeted by miR-30a-5p and modulates the $\mathrm{Wnt} / \beta$-catenin pathway in a Dkk1-dependent manner during glioma growth. Cancer Lett 331: 211-219, 2013

37. Killick SB, Bown N, Cavenagh J, Dokal I, Foukaneli T, Hill A, Hillmen P, Ireland R, Kulasekararaj A, Mufti G, et al: Guidelines for the diagnosis and management of adult aplastic anaemia. $\mathrm{Br}$ J Haematol 172: 187-207, 2016

38. Zhang X, Liu L, Dou C, Cheng P, Liu L, Liu H, Ren S, Wang C, Jia S, Chen L, et al: PPAR Gamma-regulated MicroRNA 199a-5p underlies bone marrow adiposity in aplastic anemia. Mol Ther Nucleic Acids 17: 678-687, 2019

39. Nandy SB, Mohanty S, Singh M, Behari M and Airan B Fibroblast Growth Factor-2 alone as an efficient inducer for differentiation of human bone marrow mesenchymal stem cells into dopaminergic neurons. J Biomed Sci 21: 83, 2014

40. Wang D, Wang Y, Xu S, Wang F, Wang B, Han K, Sun D and Li L: Epigallocatechin-3-gallate protects against hydrogen peroxide-induced inhibition of osteogenic differentiation of human bone marrow-derived mesenchymal stem cells. Stem Cells Int 2016: 7532798, 2016.

41. Zhang H, Zhang B, Tao Y, Cheng M, Hu J, Xu M and Chen $\mathrm{H}$ : Isolation and characterization of mesenchymal stem cells from whole human umbilical cord applying a single enzyme approach. Cell Biochem Funct 30: 643-649, 2012

42. Andrews FV, Kim SM, Edwards L and Schlezinger JJ: Identifying adipogenic chemicals: Disparate effects in 3T3-L1, OP9 and primary mesenchymal multipotent cell models. Toxicol In Vitro 67: 104904, 2020.

43. Zhang S, Zhao C, Liu S, Wang Y, Zhao Y, Guan W and Zhu Z: Characteristics and multi-lineage differentiation of bone marrow mesenchymal stem cells derived from the Tibetan mastiff. Mol Med Rep 18: 2097-2109, 2018.

44. Livak KJ and Schmittgen TD: Analysis of relative gene expression data using real-time quantitative PCR and the 2(-Delta Delta C(T)) method. Methods 25: 402-408, 2001.

45. Sakai T, Nishida Y, Hamada S, Koike H, Ikuta K, Ota T and Ishiguro N: Immunohistochemical staining with non-phospho $\beta$-catenin as a diagnostic and prognostic tool of COX-2 inhibitor therapy for patients with extra-peritoneal desmoid-type fibromatosis. Diagn Pathol 12: 66, 2017.

46. Yoshida Y, Yamasaki S, Oi K, Kuranobu T, Nojima T, Miyaki S, Ida $\mathrm{H}$ and Sugiyama E: IL-1 $\beta$ enhances wnt signal by inhibiting DKK1. Inflammation 41: 1945-1954, 2018.

47. Jumpertz S, Hennes T, Asare Y, Schutz AK and Bernhagen J: CSN5/JAB1 suppresses the WNT inhibitor DKK1 in colorecta cancer cells. Cell Signal 34: 38-46, 2017.

48. El-Mahgoub ER, Ahmed E, Afifi RA, Kamal MA and Mousa SM: Mesenchymal stem cells from pediatric patients with aplastic anemia: Isolation, characterization, adipogenic, and osteogenic differentiation. Fetal Pediatr Pathol 33: 9-15, 2014.
49. Medinger M, Drexler B, Lengerke $\mathrm{C}$ and Passweg J: Pathogenesis of acquired aplastic anemia and the role of the bone marrow microenvironment. Front Oncol 8: 587, 2018

50. Gonzaga VF, Wenceslau CV, Lisboa GS, Frare EO and Kerkis I: Mesenchymal stem cell benefits observed in bone marrow failure and acquired aplastic anemia. Stem Cells Int 2017: 8076529, 2017.

51. Li Y, Wang F, Guo R, Zhang Y, Chen D, Li X, Tian W, Xie X and Jiang Z: Exosomal sphingosine 1-phosphate secreted by mesenchymal stem cells regulated Treg/Th17 balance in aplastic anemia. IUBMB Life 71: 1284-1292, 2019.

52. Sieff CA: Introduction to acquired and inherited bone marrow failure. Hematol Oncol Clin North Am 32: 569-580, 2018.

53. Luzzatto L and Risitano AM: Advances in understanding the pathogenesis of acquired aplastic anaemia. Br J Haematol 182: 758-776, 2018.

54. Wang J, Liu X, Hao C, Lu Y, Duan X, Liang R, Gao G and Zhang T: MEG3 modulates TIGIT expression and CD $4+$ T cell activation through absorbing miR-23a. Mol Cell Biochem 454: 67-76, 2019.

55. Giudice V, Banaszak LG, Gutierrez-Rodrigues F, Kajigaya S, Panjwani R, Ibanez MDPF, Rios O, Bleck CK, Stempinski ES, Raffo DQ, et al: Circulating exosomal microRNAs in acquired aplastic anemia and myelodysplastic syndromes. Haematologica 103: 1150-1159, 2018

56. Wang Y, Niu ZY, Guo YJ, Wang LH, Lin FR and Zhang JY: IL-11 promotes the treatment efficacy of hematopoietic stem cell transplant therapy in aplastic anemia model mice through a NF- $\kappa$ B/microRNA-204/thrombopoietin regulatory axis. Exp Mol Med 49: e410, 2017.

57. Lundback V, Kulyte A, Strawbridge RJ, Ryden M, Arner P, Marcus C and Dahlman I: FAM13A and POM121C are candidate genes for fasting insulin: Functional follow-up analysis of a genome-wide association study. Diabetologia 61: 1112-1123, 2018.

58. Wardhana DA, Ikeda K, Barinda AJ, Nugroho DB, Qurania KR, Yagi K, Miyata K, Oike Y, Hirata KI and Emoto N: Family with sequence similarity 13 , member A modulates adipocyte insulin signaling and preserves systemic metabolic homeostasis. Proc Nat Acad Sci USA 115: 1529-1534, 2018.

59. Lin X, Liou YH, Li Y, Gong L, Li Y, Hao Y, Pham B, Xu S, Jiang Z, Li L, et al: FAM13A represses AMPK activity and regulates hepatic glucose and lipid metabolism. iScience 23: 100928, 2020.

60. Tang J, Zhou H, Sahay K, Xu W, Yang J, Zhang W and Chen W: Obesity-associated family with sequence similarity 13 , member A (FAM13A) is dispensable for adipose development and insulin sensitivity. Int J Obes (Lond) 43: 1269-1280, 2019.

61. Xu C, Wang J, Zhu T, Shen Y, Tang X, Fang L and Xu Y: Cross-talking between PPAR and WNT signaling and its regulation in mesenchymal stem cell differentiation. Curr Stem Cell Res Ther 11: 247-254, 2016.

62. Yuan Z, Li Q, Luo S, Liu Z, Luo D, Zhang B, Zhang D, Rao P and Xiao J: PPAR $\gamma$ and Wnt signaling in adipogenic and osteogenic differentiation of mesenchymal stem cells. Curr Stem Cell Res Ther 11: 216-225, 2016.

63. Hou X, Wang Z, Ding F, He Y, Wang P, Liu X, Xu F, Wang J and Yang Y: Taurine transporter regulates adipogenic differentiation of human adipose-derived stem cells through affecting Wnt $/ \beta$-catenin signaling pathway. Int J Biol Sci 15: 1104-1112, 2019.

64. Qi Q, Wang Y, Wang X, Yang J, Xie Y, Zhou J, Li X and Wang B: Histone demethylase KDM4A regulates adipogenic and osteogenic differentiation via epigenetic regulation of $\mathrm{C} / \mathrm{EBP} \alpha$ and canonical Wnt signaling. Cell Mol Life Sci 77: 2407-2421, 2020.

65. Ai G, Meng M, Wang L, Shao X, Li Y, Cheng J, Tong X and Cheng Z: microRNA-196a promotes osteogenic differentiation and inhibit adipogenic differentiation of adipose stem cells via regulating $\beta$-catenin pathway. Am J Transl Res 11: 3081-3091, 2019.

66. Chen XJ, Shen YS, He MC, Yang F, Yang P, Pang FX, He W, Cao YM and Wei QS: Polydatin promotes the osteogenic differentiation of human bone mesenchymal stem cells by activating the BMP2-Wnt/beta-catenin signaling pathway. Biomed Pharmacother 112: 108746, 2019.

67. Shuai Y, Yang R, Mu R, Yu Y, Rong L and Jin L: MiR-199a-3p mediates the adipogenic differentiation of bone marrow-derived mesenchymal stem cells by regulating KDM6A/WNT signaling. Life Sci 220: 84-91, 2019.

This work is licensed under a Creative Commons Attribution-NonCommercial-NoDerivatives 4.0 International (CC BY-NC-ND 4.0) License. 